\title{
Preferred information sources and needs of cancer patients on disease symptoms and management: a cross-sectional study
}

This article was published in the following Dove Press journal:

Patient Preference and Adherence

29 September 2016

Number of times this article has been viewed

\author{
Abebe Basazn Mekuria' \\ Daniel Asfaw Erku² \\ Sewunet Admasu Belachew ${ }^{3}$ \\ 'Department of Pharmacology, \\ ${ }^{2}$ Department of Pharmaceutical \\ Chemistry, ${ }^{3}$ Department of \\ Clinical Pharmacy, School of \\ Pharmacy, University of Gondar, \\ Gondar, Ethiopia
}

Purpose: This study aimed at identifying the information needs of cancer patients, their preferences for the means of receiving health information, and the perceived level of satisfaction of existing possibilities for acquiring cancer-related information in Ethiopia.

Materials and methods: An institutional-based cross-sectional survey was employed on 556 cancer patients undergoing chemotherapy in the oncology wards of Gondar University Referral Hospital and Tikur Anbesa Specialized Hospital. Data were collected through interviewer-administered questionnaire.

Results: The principal information regarded as the most important by the majority of them $(67.26 \%)$ concerned information on the specific type of cancer (name and stage of cancer), followed by the side effects of chemotherapy and their management (63.29\%) and "prognosis (survival)" (51.8\%). Doctors were the overwhelming information source about cancer $(88.8 \%)$, followed by nurses $(34 \%)$. The majority of respondents $(70.3 \%)$ were not satisfied at all or satisfied a little, while $15.6 \%$ of respondents reported that they were "quite" or "very" satisfied with the existing possibilities for acquiring information regarding cancer.

Conclusion: Medical practitioners other than doctors and nurses such as clinical pharmacists should support and identify measures that can enhance patients' satisfaction level regarding the existing possibilities for acquiring information regarding cancer. Periodic assessment of cancer patient's information requirements is also crucial, considering the ever-changing dynamics of priorities of such information desires.

Keywords: information seeking, preference, cancer, Ethiopia

\section{Introduction}

Today, understanding is growing about the implication of involving cancer patients in decision making about their care, with the literature identifying an association between involvement in decision making by patients and improved patient satisfaction. ${ }^{1}$ Both the diagnosis and management of cancer require patients to be aware of many areas of their disease. As a result, the need for extra information concerning cancer diagnosis, management, and prognosis to support clients in making informed decisions is extremely important. ${ }^{2}$

Currently, information behavior is a chosen term utilized to clearly show the ways in which human beings network with information; particularly, the manner in which people look for and use information. ${ }^{3}$ Provision of appropriate information to cancer patients has a weighty impact on heightening the quality of cancer care across the whole cancer victim community. The major aim behind information provision is to make patients ready for their treatment, to heighten adherence to therapy, to increase
Correspondence: Abebe Basazn Mekuria Department of Pharmacology, School of Pharmacy, University of Gondar, PO Box 196, Gondar, Ethiopia $\mathrm{Fax}+25$ I 58 II 4 I240 Email abeyohannes2I@gmail.com 
their strength of living with the disease, and to ensure recovery. ${ }^{4}$ Concerning studies, the fundamental role of information seeking and acquisition is in enabling a person to handle the initial diagnosis and the ongoing impacts of the life-threatening illness. ${ }^{5}$ Although the rationality behind variation in information based on the cancer site is still widely undiscovered, a recent study revealed that patient-tailored information addresses enough amount of information with the appropriate type. ${ }^{6}$ In a recent population-based study, it was reported that the pace of information seeking varied by the tumor type: patients with colorectal cancer reported consistently less information seeking than breast or prostate cancer patients did, and the differences were most prominent in patients with early-stage disease. ${ }^{7}$ Cancer patients' need of information significantly differs among individuals. Researchers have found that patients' demographics, the situations during illness, and their mentality establish the need for and receptivity to cancer-related information. Demographics of cancer patients that determine information needs are age group, educational status, and sex. Concurrently, several aspects of their condition, such as time since diagnosis, treatment chosen, disease severity, and their role to take part in making decisions regarding treatment, may influence the need for cancer and cancer-related information. ${ }^{8,9}$

Studies conducted elsewhere in the globe identified illness information, information regarding treatment, and family members' risk of getting cancer as the foremost needs of information for cancer patients, while information about sexual and psychological concerns in addition to social activities were reported as the least vital informational needs. ${ }^{10,11}$ Given that most Ethiopians having cancer today have enhanced chance of surviving the first 5 years after their first diagnosis than patients who are diagnosed a decade ago, ${ }^{12}$ it is imperative to understand the varying information desires of cancer survivors, including patients on chemotherapy. The objectives of this study were to point out information needs, patient preferences for the means of receiving health information, and the perceived degree of satisfaction of their current possibilities for acquiring information.

\section{Materials and methods}

\section{Study design and setting}

An institutional-based cross-sectional study was conducted to assess information-seeking behavior and preferred sources of information among adult cancer patients on follow-up at the oncology centers of Gondar University Referral Hospital (GURH) and Tikur Anbesa Specialized Hospital (TASH), the only hospitals in the country where cancer treatment and palliative care are provided. TASH, located in Addis Ababa, is the only institution in the country where radiology service is being provided with $>20$ beds for cancer care. ${ }^{13}$ GURH is the oldest teaching hospitals in Ethiopia located in northwest Ethiopia. It has a recently established oncology center, which is the only chemotherapy center located in the northern region of Ethiopia. The study period was from October 2015 to December 2015.

\section{Sampling}

A convenience sample of adult cancer patients who attended outpatient clinics at TASH and GURH between October 2015 and December 2015 (a total of 610 patients) were invited to participate. Adult ( $>18$ years old) cancer patients regardless of stage, time since diagnosis, or status of treatment and those who were capable of understanding the questionnaire were included in the study, while patients who had severe physical or psychological problems or those who were not willing to participate were excluded.

\section{Data collection and management}

The data collection format used was adopted from the previously peer-reviewed studies ${ }^{9,10}$ after adequate modifications. The final questionnaire included two parts: part one included demographic items (age, marital status, sex, level of education, and income) and clinical information (cancer type and date of diagnosis). Part two included items related to the importance of various cancer topics, usual and preferred sources of cancer information and the extent to which these sources of information were trusted, and favored formats for receiving cancer information. Data were collected by three well-trained nurses through interviewer-administered questionnaires. The questionnaire, originally written in English, was translated to local language (Amharic) and back to English in order to ensure that the translated version gives the proper meaning. The content validity of the questionnaire was confirmed by a team of experts, including oncology physicians, health information experts, and clinical pharmacists. The questionnaire was pretested on 25 cancer patients prior to the real data collection, which was excluded from the final study, and relevant modifications were instituted.

\section{Statistical analysis}

The final data collection tool was ensured for completeness, and responses were entered into and analyzed by the Statistical Package for the Social Sciences software Version 21.0 for Windows. Characteristics of study participants and the sources and types of cancer information used 
were briefly described using frequencies and percentages. Chi-square test and the Kendall's tau test for ordinal data were employed to compare categorical variables.${ }^{14}$ Correlations between the clinical parameters were assessed by the Spearman's correlation test. $P$-value was from two-sided tests and compared to a significance level of $5 \%$.

\section{Ethical consideration}

This study was approved by the Ethical Committee of the University of Gondar. Permission was also obtained from the oncology ward of GURH and TASH. Written informed consent from the patients was also obtained before conducting this study. The obtained information from the participants was kept confidential. The participants were also told that participation was voluntary.

\section{Results}

Out of 610 cancer patients who came to the designated oncology clinics during the study period, 556 (response rate $91.1 \%$ ) were included in the study. The majority of the nonrespondents $(67 \%)$ were receiving palliative care than were those included in the study (19\%). Disinterest and not feeling up to it were explanations commonly offered by the nonrespondents. The sociodemographic and disease-related characteristics of the study subjects were tabularized in Table 1. More than half of the respondents $(54.5 \%)$ were females, and the rest $(45.52 \%)$ were males with a female to male ratio of $1.21: 1$. The mean age of patients was $41.42 \pm 17.53$ years. A majority ( $34.5 \%$ ) of them were in the age group of $30-49$ years followed by $50-59$ years (30.9\%). Approximately half of the respondents (53.1\%) were married, and approximately one-third of the respondents (40.5\%) attended secondary school. Most of the respondents were housewives (21.9\%) or government employees (20.3\%). The most common cancer diagnosed in patients of both sexes was breast cancer (30.9\%). Hematologic malignancies (30\%) and gynecologic malignancies were the second most commonly cancers diagnosed among females (17.1\%). The respondents were asked to answer how vital (important) they considered the items listed in Table 2 that motivated them to seek information on cancer. Their answer indicated that the principal information considered as the most central by the majority of respondents (67.3\%) was "information on specific cancer type (name and stage of cancer)", which was directly related to younger age $(P=0.036)$. It's also differ notably by site of cancer $(P=0.021)$. It was highest among respondents with hematologic and gastrointestinal malignancies and lowest among respondents with gynecologic malignancies
Table I Sociodemographic and clinical characteristics of survey respondents $(\mathrm{N}=556)$

\begin{tabular}{|c|c|}
\hline Variable & Frequency, n (\%) \\
\hline \multicolumn{2}{|l|}{ Age group, years } \\
\hline $18-29$ & $102(18.3)$ \\
\hline $30-49$ & $214(38.5)$ \\
\hline $50-59$ & $172(30.9)$ \\
\hline$>60$ & $68(12.3)$ \\
\hline \multicolumn{2}{|l|}{ Sex } \\
\hline Male & $253(45.5)$ \\
\hline Female & $303(54.5)$ \\
\hline \multicolumn{2}{|l|}{ Marital status } \\
\hline Unmarried & $89(16)$ \\
\hline Married & $295(53.1)$ \\
\hline Divorced & $60(10.8)$ \\
\hline Widowed & $112(20.1)$ \\
\hline \multicolumn{2}{|l|}{ Education level } \\
\hline Illiterate & $124(22.3)$ \\
\hline Primary school & $84(15.1)$ \\
\hline Secondary school & $225(40.5)$ \\
\hline College/university & $123(22.1)$ \\
\hline \multicolumn{2}{|l|}{ Occupational status } \\
\hline Student & $69(12.4)$ \\
\hline Government employee & II $3(20.3)$ \\
\hline Merchant & $99(17.8)$ \\
\hline Housewife & $122(21.9)$ \\
\hline Farmer & $110(19.8)$ \\
\hline Private company employee & $43(7.7)$ \\
\hline \multicolumn{2}{|l|}{ Site of malignancy } \\
\hline Breast & $172(30.9)$ \\
\hline Hematologic & $167(30)$ \\
\hline Gynecologic $^{\mathrm{a}}$ & $95(17.2)$ \\
\hline Gastrointestinal $^{b}$ & $93(16.7)$ \\
\hline Others & $29(5.2)$ \\
\hline \multicolumn{2}{|l|}{ Time since treatment } \\
\hline$<6$ months & $198(35.6)$ \\
\hline 6 months to I year & $232(4 I .7)$ \\
\hline $\mathrm{I}-5$ years & $103(18.5)$ \\
\hline$>5$ years & $23(4.2)$ \\
\hline
\end{tabular}

Notes: a Ovaries, uterus or endometrium, cervix, and others. ${ }^{b}$ Stomach, pancreas, liver, colon, rectum, and anus.

and breast cancer. The next most important item reported was "side effects of chemotherapy and their management" (63.3\%), which was allied with higher level of education $(P=0.002)$ and higher income $(P=0.020)$. The third item in reported importance was "prognosis (survival)", 51.8\%, which was linked with younger age $(P<0.002)$, higher level of education $(P<0.020)$, and higher income $(P=0.002)$. Furthermore, the fourth item in reported importance was "prevention of cancer" (42\%). "Family risk" was ranked the fifth item in reported importance as a motivator to seek information for cancer $(39.8 \%)$. Patients of younger age $(P<0.032)$ and higher education $(P<0.001)$ were more worried about family risk. Cancer-related information sources 
Table 2 Rating of the importance of different information among cancer patients in Ethiopia ( $N=556)$

\begin{tabular}{|c|c|c|c|c|c|}
\hline Type of information & $\begin{array}{l}\text { Total, } \\
\text { n (\%) }\end{array}$ & $\begin{array}{l}\text { Most } \\
\text { important, n (\%) }\end{array}$ & $\begin{array}{l}\text { Important, } \\
\text { n (\%) }\end{array}$ & $\begin{array}{l}\text { Somewhat } \\
\text { important, n (\%) }\end{array}$ & $\begin{array}{l}\text { Not at all } \\
\text { important, n (\%) }\end{array}$ \\
\hline \multicolumn{6}{|l|}{ Disease } \\
\hline $\begin{array}{l}\text { Specific type of cancer } \\
\text { (including name and stage) }\end{array}$ & $556(100)$ & $374(67.3)$ & $93(16.7)$ & $80(14.4)$ & $9(1.6)$ \\
\hline Prognosis (survival) & $552(100)$ & $286(5 I .8)$ & $164(29.7)$ & $102(18.5)$ & 0 \\
\hline Prevention of cancer & $550(100)$ & $231(42)$ & $118(21.4)$ & $198(36)$ & $3(0.5)$ \\
\hline Family risk & $553(100)$ & $220(39.8)$ & $295(53.3)$ & $36(6.5)$ & $2(0.4)$ \\
\hline Coping with cancer & $553(100)$ & $147(26.6)$ & $302(54.6)$ & $226(40.9)$ & $8(1.4)$ \\
\hline Risk factors of cancer & $555(100)$ & $117(2||)$. & $271(48.8)$ & $89(16)$ & $78(14)$ \\
\hline \multicolumn{6}{|l|}{ Treatment } \\
\hline $\begin{array}{l}\text { Side effects and management of } \\
\text { chemotherapy }\end{array}$ & $553(100)$ & $350(63.3)$ & $|4|(25.5)$ & $62(11.2)$ & 0 \\
\hline Risks and benefits of treatment & $551(100)$ & $112(20.3)$ & $103(18.7)$ & $334(60.6)$ & $2(0.4)$ \\
\hline Duration and schedule of chemotherapy & $556(100)$ & $78(14)$ & $162(29.1)$ & $299(53.8)$ & $17(3)$ \\
\hline Name and aim of chemotherapy & $554(100)$ & $60(10.8)$ & $125(22.6)$ & $324(58.5)$ & $47(8.5)$ \\
\hline Complementary/alternative treatment & $556(100)$ & $50(9)$ & $193(34.7)$ & $170(30.6)$ & $143(25.7)$ \\
\hline \multicolumn{6}{|l|}{ Miscellaneous } \\
\hline Nutrition & $554(100)$ & $|4|(25.4)$ & $108(19.5)$ & $27 \mid(48.9)$ & $34(6.1)$ \\
\hline Cost of treatment & $556(100)$ & $139(25)$ & $234(42.1)$ & $161(28.9)$ & $22(3.9)$ \\
\hline Follow-up after completion & $553(100)$ & $123(22.2)$ & $288(52.1)$ & $99(17.9)$ & $43(7.8)$ \\
\hline Investigation results & $554(100)$ & $104(18.8)$ & $87(15.7)$ & $176(31.8)$ & $187(33.7)$ \\
\hline
\end{tabular}

that respondents preferred to use are shown in Table 3. Doctors were overwhelmingly the prime source $(88.84 \%)$, followed by nurses (34\%). The broadcast media, ie, television and radio, were ranked third (30.6\%). Pharmacists $(28.9 \%)$ were the fourth chosen information source regarding cancer and its treatment. Relatives/friends (12\%), another person with cancer $(2.1 \%)$, complementary or alternative practitioner (4.1\%), Internet (5\%), and other information sources were ranked much lower in favored information sources. Finally, the participants were asked about their satisfaction level regarding their current possibilities of acquiring information about cancer (Figure 1). The majority of respondents $(70.3 \%)$ stated that they were not satisfied at all or satisfied a little, with only $15.6 \%$ of the patients claiming that they were "quite" or "very" satisfied with the recent possibilities for acquiring information. Interestingly, people who were on

Table 3 Preferred sources of information for cancer patients in Ethiopia ( $\mathrm{N}=556)$

\begin{tabular}{ll}
\hline Information source & Frequency, n (\%) \\
\hline Doctors (health care providers) & $494(88.8)$ \\
Nurses & $189(34)$ \\
Broadcast media, ie, television and radio & $170(30.6)$ \\
Pharmacists & $161(28.9)$ \\
Relatives/friends & $67(12)$ \\
Did not look for cancer information & $39(7)$ \\
Internet & $28(5)$ \\
Complementary or alternative practitioner & $23(4.1)$ \\
Another person with cancer & $12(2.1)$ \\
\hline
\end{tabular}

treatment for $>5$ years $(P<0.002)$ and with a higher education level $(P=0.049)$ considered their information regarding disease condition quite satisfactory.

\section{Discussion}

Provision of education and information takes the chief part of chronic disease control.

Chronic disease patients who received education are equipped with information to take care themselves, participate in their own health care and management, and thus maximize their therapeutic outcome. ${ }^{15}$ Cancer is one of the chronic diseases that carries a major socioeconomic trouble, and its prevalence speculated to get higher in the upcoming times. ${ }^{9}$ Access to adequate and accurate information not only positively advocates good health outcomes of patients but also aids patients and their caregivers to cope up with the negative consequences of the disease starting from the detection till they receive managements. ${ }^{16,17}$ To the best of research looked for, no such study has been conducted so far in Ethiopian cancer patients. In this study, informationseeking behavior of cancer patients was critically assessed, in which supposed information needs, reported information sources, and the level of satisfaction of the current possibilities for acquiring information were included. According to their answers, information on specific cancer type (name and stage of cancer) was considered to be the foremost cancerrelated issue to be informed about (67.3\%), especially for younger patients and respondents with hematologic and 


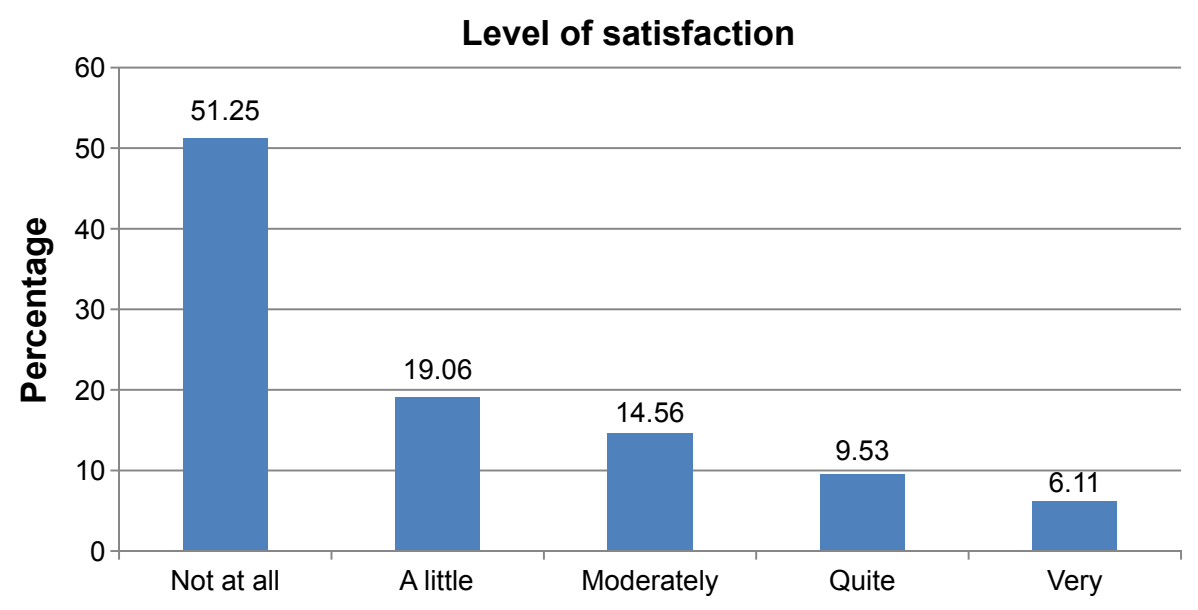

Figure I Degree of satisfaction with the current possibilities of acquiring information about cancer $(\mathrm{N}=556)$.

gastrointestinal malignancies. The patients placed side effects of chemotherapy and their management and prognosis (survival), respectively, as the second and third most important cancer-related information that they want to know about. A study done in Canada identified information about a specific cancer type (43.1\%), treatment or cures for cancer $(29.4 \%)$, and prognosis or recovery from cancer $(29 \%)$ as the three most commonly reported types of information sought. ${ }^{18}$ A similar study conducted by the National Cancer Institute revealed that out of 3,696 patients who had undergone post-treatment follow-up, specific treatment information was sought by $43 \%$, general cancer site information by $27 \%$, and prevention and risk factors information by $10 \% \cdot{ }^{19-21}$ According to a review on priority information needs of patients with cancer, the first three priority information needs were information regarding the prognosis or possibility of cure, disease stage, and treatment alternatives. ${ }^{22}$ The data regarding the reported information source indicated that $88.84 \%$ and $33.99 \%$ of the respondents declared that their physician and their nurses, respectively, were the most central source of information followed by the broadcast media (television and radio; 15.3\%). Apart from this, potential areas such as the Internet $(5 \%)$ ranked quite low in the patient-reported importance as an information source. The information sources reported in the current study contrast with the study done in Canada, ${ }^{18}$ which identifies the Internet (57.4\%) as the reliable information source for cancer patients, followed by doctors or health professionals (32.6\%), family, and friends, whereas broadcast media (television) and radio were ranked as the least trusted information sources (4.4\%). This indicates a doctor-centered health care arrangement in Ethiopia and a relative accessibility of broadcast media and radio that could alternatively be used to address information needs of cancer patients with lower income and educational level. The concept of "cancer educator" virtually lacks in Ethiopia. This in turn could point out a possible opportunity to empower and increase the role of pharmacists and other nonmedical health care providers as an information resource for cancer patients, potentially ameliorating health outcomes. Implementation of continuous, effective, and integrated multidisciplinary team-based care in the patient-care setting results in a better understanding of the pharmacist's role as a drug information expert. Many studies have reported the role of clinical pharmacists in cancer chemotherapy in different countries. ${ }^{23-26}$ In Ethiopia, there is no study done on the role of clinical pharmacists in providing health information for cancer patients. However, taking the global evidence into account and with the changing role of Ethiopian pharmacists from product-oriented to a more patient-oriented care, they have the potential to provide evidence-based information to cancer patients regarding their treatment and disease condition. There are a number of recently established drug information centers at the major university hospitals of the country, where pharmacists provide evidence-based, updated drug information and recommendation to patients as well as health care professionals. Complementary or alternative practitioners and services $(4.1 \%)$ were a least frequently reported information source in our study. This finding was supported a study done by Bennett et al, ${ }^{27}$ which revealed that among survivors of adult cancer patients $(n=836)$ in New Zealand, the role of complementary and alternative medicine services varied from $<1 \%$ up to $33 \%$ according to the service nature and patient age. Furthermore, most respondents said that use of the Internet (5\%) as a cancer-related information source was very low. This could be partially explained by the fact that in Ethiopia, there is a higher computer illiteracy and 
unfamiliarity and inaccessibility to the Internet. According to the finding, most of the respondents $(70.3 \%)$ reported that they were not satisfied at all or satisfied a little with the existing possibilities for acquiring information. Respondents who were on treatment for $>5$ years and with a higher education level considered their information about the disease quite satisfactory. This might indicate either patients' genuine satisfactory level of information regarding their disease condition and its long-term treatment or, possibly, a mistaken belief of patients that wrongly judges their level and quality of information as superior than it objectively is. Patients' level of education and their information desires go in parallel, and indeed, educational status influences information needs in different ways. One literature revealed that highly educated patients are more likely to utilize information-seeking strategies and they are successful to meet their information needs. ${ }^{28}$ However, patients with a lesser educational status may not satisfy all their information needs. The low level of satisfaction reported regarding the possibilities of acquiring information could also be partially explained by the fact that there is a huge lack of health care professionals. Ethiopia has a population of health care workers of $0.7 / 1,000$, which is very low compared with the World Health Organization recommendation of 2.3/1,000. ${ }^{29}$ Most of the doctors and pharmacists prefer to live in the urban areas, and the established drug information centers are not accessible for patients living in the rural areas. Furthermore, the cancer care and treatment in Ethiopia is very poor with only two referral hospitals (TASH and GURH) specialized in cancer treatment. Both referral hospitals have a very limited number of oncology specialists, materials with $<30$ beds, and a single radiology center. Owing to the poor health care system of Ethiopia, most patients are required to go through many referrals, starting from primary health care centers to referral hospitals. This coupled with the longer waiting times for treatment contributed to the low level of patient satisfaction with the treatment provided as well as with the existing possibilities of acquiring information.

\section{Study limitations}

The present study was done on two university hospitals, and thus the respondents, the majority of whom resided in an urban area, might not be representative of the general cancer patients of Ethiopia. As the present study included only patients following chemotherapy and relied solely on post-treatment recall of their information needs, it is recommended, for future study, to include both patients' pre- and post-treatment information needs in order to validate the findings of this study and address possible differences in patients' pre- and post-treatment information needs. Furthermore, the lack of data regarding the patients' cancer stage could potentially introduce bias in the study as some of the information needs may vary according to the severity of the disease.

\section{Conclusion}

This study showed that information on cancer type was the central information that the patients were keen to know about. The physicians, nurses, and broadcast media are among the top information sources, and the majority of patients were not satisfied with the potentials of acquiring information. Health care providers other than doctors and nurses such as clinical pharmacists should support and identify measures that can enhance patients' level of satisfaction regarding the possibilities of acquiring information about cancer. With their graduate education and patient-centered training, clinical pharmacists are well poised to meet patients' information desires by educating them about different treatments and their consequences. Periodic assessment of cancer patient's information interests is also indispensable for excellent health outcome.

\section{Acknowledgment}

The authors acknowledge the staff of GURH and TASH oncology wards for their cooperation during data collection.

\section{Authors contributions}

All authors contributed toward data analysis, drafting and critically revising the paper and agree to be accountable for all aspects of the work.

\section{Disclosure}

The authors report no conflicts of interest in this work.

\section{References}

1. Lock KK, Willson B. Information needs of cancer patients receiving chemotherapy in an ambulatory-care setting. Can J Nurs Res. 2002; 34(4):83-93.

2. Mesters I, van den Borne B, De Boer M, Pruyn J. Measuring information needs among cancer patients. Patient Educ Coun. 2001;43(3): 253-262.

3. Wilson TD. Information behaviour: an interdisciplinary perspective. Inf Process Manag. 1997;33(4):551-572.

4. Van der Meulen N, Jansen J, van Dulmen S, Bensing J, van Weert J. Interventions to improve recall of medical information in cancer patients: a systematic review of the literature. Psychooncology. 2008;17(9): 857-868.

5. Mills ME, Davidson R. Cancer patients' sources of information: use and quality issues. Psychooncology. 2002;11(5):371-378. 
6. Nicolaije KA, Husson O, Ezendam NP, et al. Endometrial cancer survivors are unsatisfied with received information about diagnosis, treatment and follow-up: a study from the population-based profiles registry. Patient Educ Couns. 2012;88(3):427-435.

7. Nagler RH, Gray SW, Romantan A, et al. Differences in information seeking among breast, prostate, and colorectal cancer patients: results from a population-based survey. Patient Educ Couns. 2010; 81(supp1):S54-S62.

8. Miller SM. Monitoring versus blunting styles of coping with cancer influence the information patients want and need about their disease. Implications for cancer screening and management. Cancer. 1995; 76(2):167-177.

9. Mills ME, Sullivan K. The importance of information giving for patients newly diagnosed with cancer: a review of the literature. J Clin Nurs 1999;8(6):631-642.

10. Graydon J, Galloway S, Palmer-Wickham S, et al. Information needs of women during early treatment for breast Cancer. J Adv Nurs. 1997; 26(1):59-64.

11. Galloway S, Graydon J, Harrison D, et al. Informational needs of women with a recent diagnosis of breast cancer: development and initial testing of a tool. J Adv Nurs. 1997;25(6):1175-1183.

12. Tigeneh W. Pattern of cancer in Tikur Anbessa specialized hospital oncology center in Ethiopia from 1998 to 2010. Int J Cancer Res Mol Mech. 2015:1.1:1-5.

13. The International Network for Cancer Treatment and Research (INCTR). Partner Profile in Cancer Medicine. Tikur Anbessa (Black Lion), Adds Ababa, Ethiopia Specialized Hospital; 2014. Available from: http:// www.inctr.org/network-magazine/current-edition/partner-profile/tikuranbessa-black-lion-hospital/. Accessed February 1, 2015.

14. Christensen D. Fast algorithms for the calculation of Kendall's $\tau$. Computat Stat. 2005;20:51-62.

15. Mazzuca SA. Does patient education in chronic disease have therapeutic value? J Chronic Dis. 1982;35(7):521-529.

16. Dale J, Jatsch W, Hughes N, Pearce A, Meystre C. Information needs and prostate cancer: the development of a systematic means of identification. BJU Int. 2004;94(1):63-69.

17. Rutten LJ, Arora NK, Bakos AD, Aziz N, Rowland J. Information needs and sources of information among cancer patients: a systematic review of research (1980-2003). Patient Educ Couns. 2005;57(3): 250-261.
18. Shea-Budgell MA, Kostaras X, Myhill KP, Hagen NA. Information needs and sources of information for patients during cancer follow-up. Curr Oncol. 2014;21(4):165-173.

19. Douma KF, Koning CC, Zandbelt LC, de Haes HC, Smets EM. Do patients' information needs decrease over the course of radiotherapy? Support Care Cancer. 2012;20(9):2167-2176.

20. Squiers L, Finney Rutten LJ, Treiman K, Bright MA, Hesse B. Cancer patients' information needs across the cancer care continuum: evidence from the cancer information service. J Health Commun 2005;10(suppl 1):15-34.

21. Basch EM, Thaler HT, Shi W, Yakren S, Schrag D. Use of information resources by patients with cancer and their companions. Cancer. 2004; 100(11):2476-2483.

22. Tariman JD, Doorenbos A, Schepp KG, Singhal S, Berry DL. Information needs priorities in patients diagnosed with cancer: a systematic review. J Adv Pract Oncol. 2014;2014(5):115-122.

23. McKee M, Frei BL, Garcia A, Fike D, Soefje SA. Impact of clinical pharmacy services on patients in an outpatient chemotherapy academic clinic. J Oncol Pharm Pract. 2011;17(4):387-394.

24. Ruder AD, Smith DL, Madsen MT, Kass FH 3rd. Is there a benefit to having a clinical oncology pharmacist on staff at a community oncology clinic? J Oncol Pharm Pract. 2011;17(4):425-432.

25. Shah S, Dowell J, Greene S. Evaluation of clinical pharmacy services in a hematology/oncology outpatient setting. Ann Pharmacother. 2006; 40(9):1527-1533

26. Valgus JM, Faso A, Gregory KM, et al. Integration of a clinical pharmacist into the hematology-oncology clinics at an academic medical center. Am J Health Syst Pharm. 2011;68(7):613-619.

27. Bennett JA, Cameron LD, Whitehead LC, Porter D. Differences between older and younger cancer survivors in seeking cancer information and using complementary/alternative medicine. J Gen Intern Med. 2009;24(10):1089-1094.

28. Carlsson M. Cancer patients seeking information from sources outside the health care system. Support Care Cancer. 2000;8(6):453-457.

29. No author. Health Sector Development Programme IV, 2010/20112014/2015. Final Draft ( $p d f 780.81 \mathrm{~kb}$ ). Addis Ababa: Government of Ethiopia, Ministry of Health; 2010. Available from: http://phe-ethiopia. org/admin/uploads/attachment-721-HSDP\%20IV\%20Final\%20 Draft\%2011Octoberr\%202010.pdf. Accessed February 1, 2015.
Patient Preference and Adherence

\section{Publish your work in this journal}

Patient Preference and Adherence is an international, peer-reviewed, open access journal that focuses on the growing importance of patient preference and adherence throughout the therapeutic continuum. Patient satisfaction, acceptability, quality of life, compliance, persistence and their role in developing new therapeutic modalities and compounds to optimize

\section{Dovepress}

clinical outcomes for existing disease states are major areas of interest for the journal. This journal has been accepted for indexing on PubMed Central. The manuscript management system is completely online and includes a very quick and fair peer-review system, which is all easy to use. Visit http://www. dovepress.com/testimonials.php to read real quotes from published authors. 